\title{
Beyond folding and gathering: museums attending to the new materiality
}

Kylie Budge*

\begin{abstract}
Museums are attending to matters of technique in relation to objects and exhibitions suggesting a new or renewed interest in creative practice and how objects are made. This focus parallels practices and changes occurring in broader society. In this article I argue that a rise in attending to technique extends what various theorists have referred to as the 'material turn' in a dimension that underscores creative process and making. I do so by exploring two recent exhibitions, one in Israel and another in Australia, which have brought the notion of technique into focus through the context of textiles and other materials such as paper, porcelain, wood and metal. Through their emphasis on 'gathering' and 'folding', the construction of textiles and other forms are accentuated for public exploration, fostering new understandings of technique. Conclusions are drawn connecting museum contexts with that of broader society in reference to making, the role of the hand, and craft processes.
\end{abstract}

Key words: museums, materiality, exhibitions, technique, craft

\section{Introduction}

This article focuses on how and why museums are attending to objects and matters of technique through exhibitions, particularly those with a strong textile focus. In doing so it asks how this might relate to the attention that has come about through a renewed interest in matter, the real physical stuff of which the world is made (Barrett and Bolt; 2013; Dudley 2010; Bennett 2010; Barad 2007; Coole and Frost 2010), and the way museums, as custodians of significant material matter are increasingly engaged with the subject of objects and how they are made. A renewed emphasis in the area of technique, particularly in relation to process and the role of the hand, is coming to the fore (Gauntlett 2011) and is therefore of focus in this article. Museum exhibitions have increasingly shown an interest in the subject of the handmade and of making in general. However, as Budge (2016) has argued, this relationship is not new.

Museums have had a history of attending to matters of craft through their focus on collecting and exhibiting folk art, indigenous cultural artefacts and various other objects of material culture that some categorize as 'craft' or 'decorative arts' (see, e.g., The Louvre in France, National Museum of Ireland and the Brooklyn Museum in New York). (p.80).

Dean argues that the main motivation of museum exhibitions is to 'serve the public' (2002: 12), and therefore, connections and alignment between museum intent and mission statements, approaches to exhibitions, including content, and the way in which they address audiences is key. Exhibitions play a critical role in the communication of ideas by a museum because exhibition form and content serve as 'prompts' taken up and experienced by the visitor 'as a situated, differentiated and relatively complex process' (Macdonald 2007: 152). Achiam (2012) argues compellingly that the content of exhibitions is under-researched and that the literature 
shows an emphasis on the exhibit and audience. Unlike much exhibition research that seeks to understand the visitor or audience experience and interpretation of exhibitions (Achiam 2012; Macdonald 2007), this article takes the exhibition curatorial theme and content as its particular perspective for its investigation.

The research was driven by the following questions: why are museums currently attending to matters of technique through exhibitions and what can be learned from such a focus? Questions extending from this were: why deconstruct an object through the notion of 'technique' in a museum context and why might this be of value? These questions were asked not because there is a suggestion that attending to technique is new to museums. According to Gille (1986) museums have been addressing the notion of technique since the Science Museum opened in London in 1857. Rather, such questions were asked in relation to the current, twenty-first century interest in and emphasis on technique within design and making.

Using a case study approach as a means of generating data (Yin 2013) I explored two exhibitions, 'Japanese Folds' exhibited at the Museum of Applied Arts and Sciences in Sydney, Australia from May 16 - June 21, 2015 and 'Gathering - from domestic craft to contemporary process' exhibited at the Design Museum Holon in Tel Aviv, Israel from July 3 - November 1 , 2014. With 'Japanese Folds', I was able to attend the exhibition; interview the curator; consider object and exhibit labels; web information; visuals (photographs taken in the exhibition); as well as associated education and programming information. This was possible because I live in the same city, and in addition, have ready access to materials given I work at that museum. For 'Gathering' I drew on secondary sources via the Museum website and exhibition catalogue, and interviews (both text and video) with the curator, as I was not able to attend the exhibition in person. Leinhardt and Knutson (2004) chose a similar range of methods in understanding exhibitions through their study on museum learning.

The two exhibitions were chosen for this exploration because they used a technique as the conceptual frame and title; 'gathering' and 'folding', with a primary focus on textile objects. Other considerations were the recency of both exhibitions suggesting that technique has a currency that may have played a role in their focus and the context - both exhibitions were held in museums that attend to design and applied arts. The kind of museum is worth noting in relation to the subject matter explored in this research, but does not necessarily suggest that matters of technique and their connection to the handmade, making and creative process are limited to these types of museums.

\section{Folding and gathering}

In 'Folding', as the name implies, the opposing acts of folding and unfolding were explored through the medium of contemporary Japanese fashion and decorative arts. Curator, MinJung Kim, brought this technique into focus by showcasing pre-heated pleated garments, origami folded textile lengths, kimono, an extended folded woodblock print book, porcelain folded sculpture, and 'books that transform into clothing'1 through the act of folding. Minaret was an example of how folding was articulated. The lantern-shaped dress, designed by Issey Miyake in 1995, is a complex object of pleated polyester which when folded down lies flat and becomes two dimensional. The folding elements of this work are complex, efficient and aesthetically entrancing because of the way it transforms from a three to a two dimensional object with one simple movement.

Objects from the Wizard of Jeanz collection, designed by Hiroaki Ohya in 2000, offer another transformational interpretation of folding. Incorporating an extension of the Japanese practice of origami, where flat sheets of paper are folded into elaborate and intricate forms, many of which become three dimensional, objects from the Wizard of Jeanz collection transform magically from books to folded clothing. One example is a striking red skirt with sophisticated folds and pleats incorporating materials such as cotton, printed nylon, polyester, polyurethane, and cardboard.

A third example from 'Folding' is that of a 1900-48 Japanese folded kimono made from resist-dyed and embroidered crepe silk. The kimono is deliberately displayed in its folded form highlighting the traditional Japanese practice of folding rather than hanging textiles. Exhibition labels diagrammatically illustrate the various steps involved in kimono folding to 
further accentuate this point. In the same gallery, another folded kimono hung on a traditional kimono hanger, a straight wooden rod placed horizontally through the sleeves and across the garment so that is can be displayed vertically and flat. Its inclusion illustrates the object's unfolded state, adding symmetry to the curatorial concept as it is executed in the exhibition. Highlighting the central theme of 'folding' in the exhibition, its construct as a technique and broader connections with living and thinking practices, Kim explained

Folding and unfolding is the way they live and practice their culture [in Japan]. It's embedded in their culture. So it's not only the craft process or technique but the whole architecture. When you think about architecture it's a whole concept rather than technique. There is a technique involved in making a screen or a sliding door but the division of the room and opening up the room - it's not really a technique, it's a concept, the way they live, the way they think.

Folding and unfolding the futon...using the room as a bedroom at night. The folding of futon and storing away. There is a way to fold but rather than folding techniques... why they fold and unfold...the kind of philosophy or the way they live is embedded. The living habit is embedded in their culture. So that's what I tried to say in the exhibition. And folding a kimono - there is a technique, there's a way to fold a kimono...so people have to follow but that's of secondary importance or significance. The more important thing is the thought in deciding to fold. [interview with Curator, Min-Jung Kim, June 2015]

As a technique, folding was a central conceptual theme in this exhibition that enabled materials, cultural beliefs and practices to coalesce in a manner that prompted and informed the viewer, encouraging questions and dialogue about what is being folded and why. As Kim articulates, folding was used as a technique, not only of the hand, but importantly, the mind. Traditional practices were framed in a contemporary manner and context stimulating inquiry into the techniques of focus (both folding and unfolding) as well as the wider conditions that surround and inform them.

Using gathering as a theme, The Design Museum Holon exhibition focussed on design furniture and lamps, and the renowned Japanese fashion designer Issey Miyake was featured through a survey of his collection '132. 5'. Miyake's collection used science, design and Japanese artisanal knowledge to create garments where technique is paramount ${ }^{2}$. Craft was the central conceptualizing idea of the exhibition with particular attention given to 'the humanisation of the making process... and the repetition of skills that belong to our common past, exuding a sense of belonging and continuity' ${ }^{3}$.

Li Edelkoort, an international trend forecaster, co-curated the exhibition with Philip Fimmano, focusing on 'new technologies and techniques to completely transform' domestic craft techniques such as pleating, draping, layering, ribboning, smocking, and wrapping. Edelkoort extended the concept of gathering deeper to argue that society needs to attend to 'mending and gathering' as a means to deal with new and difficult economic times ${ }^{4}$. Exhibition sources suggest the processing of methods, practices, and techniques were examined through craft and design to understand and create new ideas and objects. Thus, in this exhibition, Edelkoort's concept of gathering was used broadly to include a variety of techniques involved in the creative process that culminated in the creation of the new. Her intent was to illuminate techniques and process to encourage reflection and celebration.

The catalogue showcases ten techniques of relevance to the exhibition: draping, pleating, folding, smocking, ribboning, quilting, needlework, wrapping, layering, and baking. These feature in the exhibition through chairs such as the Promo Blanco handmade felt chair (2010) by Ayala Serfaty, the Witch Chair (2004) by Tord Boontje made from layers of leather resembling that of a shingle roof, and Fredrikson Stallard's fibreglass King Bonk Chair (2008). Lamps and lighting were featured in the exhibition too, with the inclusion of pieces such as Pleat Box Collection Lamps (2011) by Xavier Manosa and Mashallah. Each of the objects embodied various techniques such as folding, felting, draping, layering, wrapping, and baking that frame the exhibition as a whole. Works from Issey Miyake's Reality Lab series included intricately folded and pleated shirts and dresses, and garments that have been extensively 
wrapped and layered resulting in brilliant dyes.

In an interview just prior to the exhibition Edelkoort explained that gathering as a theme was important to address in the context of this exhibition because people are trying to recover from the economic crisis that has had an effect in most parts of the world since $2008^{5}$. (Edelkoort 2014) Edelkoort's curatorial intent was to create an exhibition that gathers people and materials to reframe and to reform. Through the objects she selected to be part of the exhibition she asked the viewer to consider how craft, design, and technique play a role in gathering and attending to both the material and the emotional. She connected broader questions about material culture, and our use of it, to nurture and to repair in difficult times. Moreover, her curatorial intent was to fuse notions of the handmade and machine-made through an attention to technique. In doing so, she highlights their relationships rather than dichotomises their states, as is more often the case in contemporary discourse about making and design. In doing so, she foresees an optimistic future where making via the hand and machine develops in collaboration enabling new and exciting possibilities for design and material culture (Edelkoort 2014).

\section{Common threads}

\section{Ways of living}

The notions of making and design are connected to the wider world through the exhibition themes in both 'Gathering' and 'Folding'. Gathering and folding practices are embodied with references to broader cultural life, linking the small details of technique and their material forms with questions and meditations about the choices made in how we live. In 'Gathering', this occurred by attending to ideas about comfort and the role of the handmade through technique (baking, pleating, draping, layering, ribboning, smocking, and wrapping). These techniques were connected with materials as a means of assisting the makers and viewers to gather and re-emerge strengthened from difficult global times. In 'Folding', attention was focused on culture and approaches to living through consideration of traditions and practices from Japan. The objects in the exhibition encourage the viewer to be enveloped in the details of folding and unfolding to contemplate and question the ways in which these matters are attended to in their own lives.

\section{Materials}

Through the lens of technique, the exhibitions address materials and the ways in which they can be manipulated to produce new and innovative forms. While other materials such as porcelain, paper, wood, and metal are included, the common and dominant material element of both 'Gathering' and 'Folding' is textiles. In many ways this is obvious given that the actions associated with both techniques lend themselves easily to textiles. However, what is unique to both exhibition contexts is the ways in which textiles highlight the innovative use of technique to produce unusual and in some case, transformational forms. 'Technique' acts as a framing device to understand design in relation to material conditions, and for considering bigger questions about society and the way in which we live.

\section{Process}

Creative process is brought to the fore through both 'Gathering' and 'Folding' in the decision to highlight technique and by reason of the objects chosen for display. In both contexts process plays a pivotal role enabling the manifestation of curatorial intent to be accomplished. For example, in 'Gathering', the exhibition catalogue draws attention to process by illuminating each technique and the process of making that accompanies it. In the exhibition, the objects, through their form and visible embodiment of particular techniques such as pleating, smocking, and layering, ask the viewer to consider, rather than render invisible, the role of creative process in their development. Through the objects, the viewer is drawn into asking questions about materials and the process of making. In 'Folding', the process of creating elaborate folded garments and other objects is foregrounded through the choice of objects. For example, 
a textile length, Origami Pleats, of folded, dyed and heat-set polyester, designed by Reiko Sudo in 1997, asks the viewer to consider how such an extraordinary and elegant work was created. It accomplishes this through its presence as a textile length rather than a completed garment. Others, such as the Wizard of Jeanz collection, succeed in achieving the same result because of their incredible ability to showcase the way in which a book can metamorphosize into garments.

\title{
Materiality and making
}

'Folding' and 'Gathering', with their focus on technique and materials highlight materiality and making in a museum exhibition context. Coole and Frost argue that there are 'insistent demands for more materialist modes of analysis and for new ways of thinking about matter and processes of materialization' (2010: 2) and that the 'material turn' (Barrett and Bolt 2013; Coole and Frost 2010) is marked by an increased interest in material thinking (Carter 2004). A new emphasis on materiality is, in their view, a result of a number of changes, and also a response to an exhaustion of the non-material discourses that flourished under the cultural turn, beginning in the 1970s within the social sciences and humanities (Barrett and Bolt 2013). Carter's (2004) work, too, is an important part of the material-making-thinking discourse. $\mathrm{He}$ argues that creative research involves 'material thinking' with a particular emphasis on process. He views this process as being one of connecting matter and in doing so creating and inventing. This refusal to make 'the work inseparable from what is produced' is critical to an understanding of material thinking (Carter 2004: 11).

The 'productivity and resilience of matter' (Coole and Frost 2010: 7) distinguishes material thinking from other discourses for example, constructivism. Materialists see matter and humans as actively informing each other rather than viewing matter as 'dead', unresponsive and distinctly separate from humanity. Dudley (2010) argues there is a dynamic exchange that occurs between material objects and humans, and this is the core of materiality thinking. That is, matter possesses agency, or as Ingold (2010) emphasizes, things have life. In line with such thinking, Bennett argues for a recognition of matter as encompassing a 'vital materiality' (2010: vii) and in doing so acknowledges the capacity of things that rejects the Cartesian dualism of mind and matter.

Barad (2007), a key theorist in materialism who draws on quantum physics to inform her ideas, emphasizes the necessary entanglement of subject and object. She argues the dualistic thinking that separates subject/object, mind/body, human/inanimate objects, is a limited frame and one that can serve us no longer. Instead Barad argues for 'diffraction' as a method which 'allows you to study both the nature of the apparatus and also the object' (Dolphijn and van der Tuin 2012: 52), and thus dismembers the dualistic thinking that separates the two. Emphasizing the difference in thinking involved in this framework she explains,

\begin{abstract}
Diffraction, understood using quantum physics, is not just a matter of interference, but of entanglement, an ethico-onto-epistemological matter. This difference is very important. It underlines the fact that knowing is a direct material engagement, a cutting together-apart, where cuts do violence but also open up and rework the agential conditions of possibility. There is not this knowing from a distance. Instead of there being a separation of subject and object, there is an entanglement of subject and object, which is called the 'phenomenon'. (Dolphijn and van der Tuin 2012: 52).
\end{abstract}

In Barad's view, there is much value in what can be brought from seemingly unconnected or separate areas by 'diffractively reading them through one another for their various entanglements and by being attentive to what gets excluded as well as what comes to matter' (Dolphijn and van der Tuin 2012: 52-53). As such, Barad supports the notion of a 'relational ontology' (Barad, 2007: 93), of being open to reading causations, connections, and disconnections to inform new ways of thinking and practising. There is a similarity between Barad's ideas and those of Ingold with his view of how things are entangled. Ingold argues that things (not objects) possess life, and that 'the fluxes and flows of materials' (2010: 3) through the surfaces of things creates movement and growth. 
How is technique part of materiality? Material thinking is about matter, and matter is comprised of materials that coalesce to take form (Carter 2004). In taking form, particularly with human intervention in this process, techniques are applied to shape, construct, mould, and harness the resulting arrangement. Therefore, technique plays an important role in material thinking Carter 2004) and this concurs with Dudley's argument that materiality 'connotes the form and materials of which an object consists, together with the techniques [my emphasis] by which it may have been made or formed, any additions or presentational conventions (such as a frame) which may have been added to it, and all and any traces of the passage of time and, especially, physical human interaction' (2010: 7). Further to this she adds, materiality is not 'simply physical form, but the dynamic interaction of both with our sensory experience' (2010: 8). In Barad's (2007) view, material thinking encompasses technique in terms of the relationships that occur between subject and object. Regardless of how one defines or understands the notion of material form, technique is a central component of it when human application is involved.

A material framework of thinking is an appropriate lens to consider technique in the context of museum exhibitions that highlight objects and their material creation. The craft of making and a focus on the material has a distinct dynamism that is very much about agency; particularly the agency of the hand through technique in relation to matter so that construction of new forms of material objects are created. Therefore, material thinking as understood by Barad (2007), Bennett (2010), Ingold (2010) and others (Barrett and Bolt 2013; Coole and Frost 2010) informed my interpretation and analysis of 'Folding' and 'Gathering'.

'New materialism' is a term coined by Manuel DeLanda and Rosi Braidotti in the second half of the 1990s (Dolphijn and van der Tuin 2012: 48). Such a turn is both curious and significant given the continuing rise of all things digital (Castells 2010), and the increasing amount of time people choose to spend in various virtual realms (Nielsen 2014). Some have argued that the turn to the material is a response to the increasing role of technology in our lives (Gauntlett 2011), that is, a human desire to connect with the tangible, particularly through acts of making, as a means of balancing the time spent engaging with technology (Gauntlett 2011). Through such acts, (new) meaning is made.

This is underscored through the increasing number of exhibitions that attend to notions of 'making', the 'handmade', and creative process in some form, and the number of 'maker' and 'making' related events in which cultural institutions are participating or initiating. For example, then Director of the Museum of Arts and Design in New York, Glenn Adamson, was part of the 'The future of knowing and making' event in early 2015 at the Bard Graduate Centre in the United States, and around the same time the Smithsonian American Art Museum in Washington DC held 'The craft museum: ideals and practice' event. Further examples include 'Make: Shift' a two day conference in London held in 2014 exploring 'how advances in materials, processes and technologies are driving new developments in craft practice', 6 and the Irish National Craft Gallery's conference on Contemporary Craft: Curating | Collecting | Critical Writing in early $2014^{7}$.

\section{Technique and material thinking}

The notion of 'technique' is an essential element in the process of making. Technique is defined by the Oxford dictionary as 'a way of carrying out a particular task, especially the execution or performance of an artistic work or a scientific procedure'. Bertrand Gille, author of a large twovolume work on the history of techniques, defines technique as 'a group of operations which often require different tools' (1986: 10) citing objects as constituting 'the most accurate and valuable sources' (1986: 83 ) in understanding the evolution of techniques through time. In the context of making, technique is valued in relation to the quality of the final form in which an object takes. In the context of textiles for example, technique relates to construction and the way textiles are integrated into other forms, such as dress objects or furniture.

Through both 'gathering' and 'folding', process, culture and ways of living are entangled so that the technique signified in each exhibition's name can be read diffractively (Barad 2007) to encompass meaning that is far greater than the notion of doing to carry out a particular task (the Oxford dictionary definition of technique). In Barad's view, matter is seen 'as a dynamic and 
shifting entanglements of relations, rather than a property of things' (2007: 224). A diffractive interpretation adds a richness and depth to the notion of technique that would not have been gained if the term has been read with its singular, functional meaning.

Moreover, rather than existing as an unconnected or disembodied process, through the two exhibitions the techniques of gathering and folding exist as symbols of larger elements: ways of living, and approaches to life. Both techniques suggest movement and change (Ingold, 2010), of transforming materials from one form to another, and this is reverberated through the use of verbs as titles. As curatorial intent, technique is a symbol for the transformation desired more broadly in society, or at the very least, a way to ask questions linked to notions of change.

\section{Interpretations through material thinking}

Gathering and folding are verbs that imply connecting, of bringing together and of changing material form in some manner. In the case of the two exhibitions, gathering and folding symbolize the entangling of objects (textiles, furniture, lamps, porcelain, books, and other paper forms) with the curatorial direction and intent of the exhibitions. This way of thinking about the curatorial focus of the exhibitions speaks to Ingold's notion of things as processes (2010: 8), and, in his view, the leakage that occurs between the surfaces of things adding to their life force. Ingold's argument that things are part of a 'meshwork' containing 'flows and counter-flows' (2010: 11) and Barad's ideas about matter as being comprised of a dynamic and shifting entanglement of relations (2007: 224) are important lenses in which to understand the role and place of technique in 'gathering' and 'folding' as exhibitions. Many objects in both exhibitions are embedded or entangled with the culture of Japan (both old and new), and the culture of making entangles and frames all. This is evidenced through materials chosen and the material form of the objects. This is rather like Edelkoort's notion of 'fusion' which she argues involves technology and the hand working together as we enter a new age. Thus, dichotomy and dualisms are disbanded through material thinking.

In addition, Dudley's (2010) argument that there is an exchange between objects and humans, is evident through the curatorial lens of 'technique', with the exhibitions serving as context.

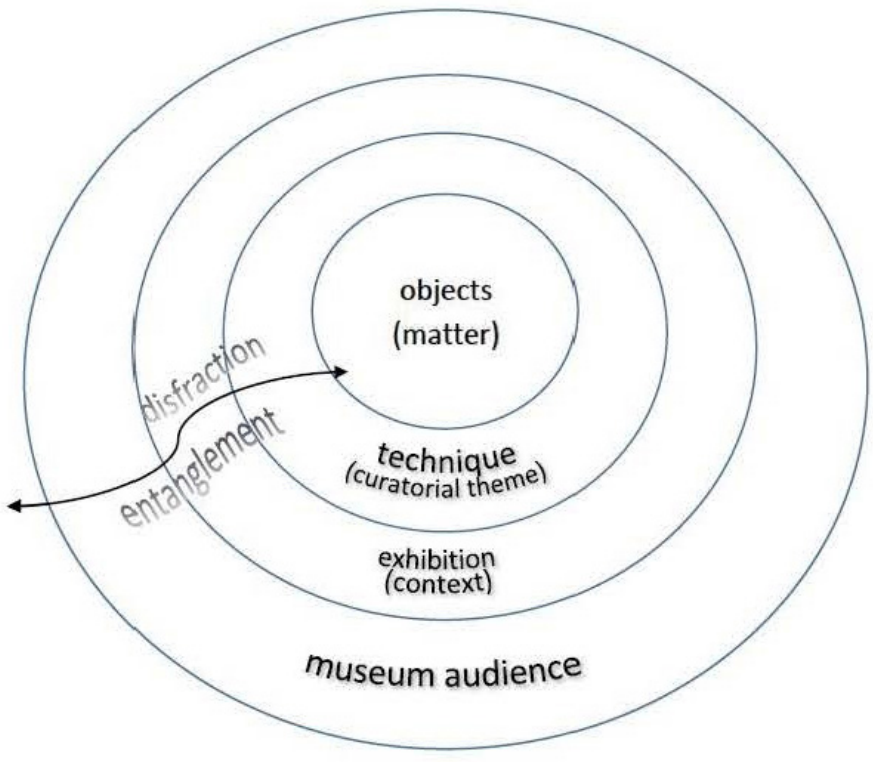

Fig 1: 'Technique' as a field for exchange Through this exchange where diffraction occurs, technique includes deeper and broader meanings. Technique becomes a dimension of material thinking that acts as a field for this exchange, where subject and object are entangled and diffracted, and new understandings are afforded. As illustrated in Figure 1, the exhibition is the context for this exchange and museum audiences are participants who have the potential to observe, interpret, analyse, and comment as part of their engagement.

In using materiality as a theoretical framework to address the research questions the notion of technique as highlighted through the two exhibitions 
has been explored and illuminated. In addressing the primary research question about why museums are attending to matters of technique through exhibitions, this research suggests that technique is used as a symbol for broader cultural issues and themes. Technique performs as a metaphor. Process and doing is still of interest in the technical sense of the notion of 'technique', but the broader driving force behind both 'Gathering' and 'Folding' as exhibitions and their choice of subject matter is about exploring belief systems, cultural practices and approaches to living.

In regards to the research sub-questions about learning from such a focus, this research suggests that learning is about society as a whole. Learning is orchestrated so that it is not necessarily focussed on the objects in the exhibition, but through the objects as material artefacts, so that their construction and deconstruction provokes questions about the way we live, the decisions we make, and the actions we create. The exhibition objects are entangled with us and the society in which we inhabit.

Further, this research suggests that deconstructing an object through technique as a frame allows for an exploration of materials, the material forms, and processes. It enables us to see the way humans and materials interact and inform each other (Dudley 2010), and they ways these elements, when they diffract (Barad 2007: 91-92), create the possibility of different or unacknowledged insights and understandings, and paths. This approach is of value because it enables the possibility of new insights that may not be possible when thinking through old frames such as dualistic or dichotomic ways of thinking.

\section{Conclusions}

The findings of this research focusing on two exhibitions attending to technique suggests a number of implications. Firstly, museums are addressing technique in a manner which extends well beyond the pragmatic, technical aspects of the term. They do this to ask questions of society, to provoke thinking about human behaviour, the way people live, and our collective use of resources. Such exhibitions push audiences to move beyond the making and design elements of 'technique' to consider implications about humanity and the planet on a grander scale. The objects and curatorial intent of exhibitions addressing technique are closely entangled to enable complex considerations and provocations. The implication being that museums have much to offer in relation to contributing new knowledge in this field through their curatorial and exhibition practices and outcomes.

Secondly, there are implications for how we understand objects in relation to decisions we make about living. Objects are often the starting point for asking provocative questions, which can then encourage and generate awareness. This activity can be a catalyst for change and in some cases, transformation. Given the central role objects perform in relation to material culture, museums can play an integral role in the development of thinking in the fields of design and making, with technique being a point of access for more substantial ideas.

The third implication stemming from this research relates to designers and makers of objects knowing that museums are an avenue for addressing the bigger issues that often underpin their work. That is, attention to technique does not have to be reduced to the mechanics of process but can be a path for exploring and elaborating on large questions about living.

Furthermore, there is a theoretical implication in regards to materiality and technique stemming from this research. Attending to the notion of technique is an important component of material thinking, extending it in a dimension to underscore creative process and making. In relation to this exhibition research, technique acts as a field for an exchange between objects, curatorial intent, and audience (as illustrated in Figure 1). Moreover, technique carries meaning that extends beyond the pragmatic and functional to include an entanglement of broader thinking and process, thus illuminating possibilities for provocation and exploration.

There are limitations to the research given the two-exhibition focus and the methodological approach undertaken and as such, generalizations should be made with caution if at all. Stemming from this, there are many possibilities for future research that have surfaced during this exploration. Future research could explore audience experience and perception in relation to the curatorial intent, and in the case of these two exhibitions, assess and critique the connection between these two areas and the questions of broader life that are alluded to by the exhibition content and explicitly stated by the curators in interviews and secondary sources. 
I have argued that the increase in attention to technique extends the material turn in a dimension that underscores creative process and making, and the broader philosophies in which these are based. Shiner (2012) asks a question about whether there is 'a subordination of process to meaning' in relation to craft, and is worth considering in the context of the research explored here. Both 'folding' and 'gathering' as exhibitions attend to craft in terms of the process of making in central ways. However, rather than subordination, an entanglement of meaning and process occurs enriching possibilities for understanding that force us to question and to think differently about the craft of design and making. If we embrace Barad's (2007) request to refrain from dichotomic thinking then there is no subordination of either process or meaning, but a creation of the new through interaction and engagement. That is, it is not a case of either process or meaning, but how they come together, diffract, entangle and suggest the new. This is what is exciting about the way cultural institutions are addressing notions of craft and making through exhibitions and public programming. In doing so, they are contributing to new knowledge about this domain, and play an important role in engaging audiences in the effort to do so.

Received: 30 July 2015 Finally accepted: 20 February 2017

\section{Notes}

1 Japanese Folds (n.d.) http://maas. museum/event/japanese-folds/, accessed 22 May 2015.

2 Fimmano, P. (n.d.) 132 5. Issey Miyake: a work of hope. http://www.dmh.org.il/pages/ default.aspx?Pageld=600\&catid=-1, accessed 22 May 2015.

3 GATHERING - From Domestic Craft to Contemporary Process, Gathering, n.d., http://www. dmh.org.il/exhibition/exhibition.aspx?pid=32\&catld=-1, accessed 22 May 2015.

4 Exhibitions - Gathering - Edelkoort, Design Museum Holon 'gathering' n.d., http://www. dmh.org.il/pages/default.aspx?Pageld=588\&Preview=1, accessed 22 June 2015.

5 Li Edelkoort talks about GATHERING her new exhibition at Design Museum Holon, Israel, 2014 (video file), https://www.youtube.com/watch?v=n2f6ajmu1eE, accessed 14 July 2015.

6 Crafts Council (n.d.). http://www.craftscouncil.org.uk/what-we-do/makeshift/ accessed 2 April 2015.

7 National Craft Gallery (n.d.). http://www.nationalcraftgallery.ie/learn/seminars, accessed 16 March 2015.

\section{References}

Achiam, M. (2012) 'Museum exhibition research', 1 Workshop Internacional de Pesquisa em Educacão em Museus, 1-10. GEENF, Universidade de São Paulo. http://www. geenf.fe.usp.br/v2/wp-content/uploads/2013/01/Conf2_Marianne-protegido.pdf, accessed 22 May 2015.

Barad, K. (2007) Meeting the universe halfway: quantum physics and the entanglement of matter and meaning, Durham, North Carolina: Duke University Press.

Barrett, E. and Bolt, B. (2013) Carnal knowledge: towards a 'new materialism' through the arts, London: I.B. Taurus.

Bennet, J. (2010). Vibrant Matter, Durham, USA: Duke University Press.

Budge, K. (2016). The 'new' craft phenomena and the contemporary museum, Craft Research, 7 (1) 79-89. 
Carter, P. (2004) Material Thinking: The Theory and Practice of Creative Research, Melbourne University Press, Melbourne.

Castells, M. (2010) The rise of the network society, Wiley-Blackwell, UK.

Coole, D. and Frost, S. (2010) 'Introducing the new materialisms', in Diana Coole and Samantha Frost (eds) New materialisms, 1-43, Durham USA: Duke University.

Dean, D. (2002) Museum exhibition: theory and practice, London: Routledge.

Design Museum Holon (2014) Gathering - From Domestic Craft to Contemporary Process, Exhibition catalogue, Design Museum Holon, Israel.

Dolphijn, R. and van der Tuin, I. (2012) New Materialism: Interviews \& Cartographies, Michigan Publishing: Open Humanities Press.

Dudley, S. (2010) Museum materialities: objects, engagements, interpretations, London and New York: Routledge.

Gauntlett, D. (2011) Making is Connecting: The Social Meaning of Creativity, from DIY and knitting to YouTube and Web 2.0, Cambridge, UK: Polity Press.

Gille, B. (1986) The history of techniques, Volume 1, Switzerland: Gordon \& Breach Science Publishers.

Ingold, T. (2010). Bringing things to life: creative entanglements in a world of materials. NCRM Working Paper Series, 05/10, ESRC National Centre for Research Methods.

Leinhardt, G. and Knutson, K. (2004) Listening in on museum conversations, Walnut Creek, CA: AltaMira Press.

Macdonald, S. (2007) 'Interconnecting: museum visiting and exhibition design', CoDesign: International Journal of CoCreation in Design and the Arts, 3 (1) 149-162.

Shiner, L. (2012) 'Art's Abject Other or the "New Cool"? Should Philosophy Rethink the Art/ Craft Dichotomy?', Aesthetics, http://aesthetics-online.org/?page=ShinerArtCraft, accessed 15 May 2015.

Yin, R. K. (2013) Case study research: design and methods, Los Angeles, CA: Sage.

*Dr Kylie Budge is Research Manager at the Museum of Applied Arts and Sciences in Sydney, NSW. Prior to this she worked in the university sector for many years in Melbourne holding senior lecturer and lecturer positions working with art and design disciplines. Kylie completed her PhD at the University of Melbourne where the focus of her research was creative practice and the teaching of art and design in higher education. Her research interests include art, design and creativity; digital cultures; creative process and practice; creativity; embodied and tacit knowing; and materiality.

Dr Kylie Budge

Research Manager

Museum of Applied Arts and Sciences

500 Harris St

Ultimo, 2007

NSW

Australia

Kylie.bduge@maas.museum 